\title{
HUBUNGAN DUKUNGAN KELUARGA DENGAN KEPATUHAN IBU DALAM PEMBERIAN IMUNISASI DASAR LENGKAP PADA BALITA USIA 12-23 BULAN DI LINGKUNGAN ARUM TIMUR MELAYA
}

\section{THE RELATIONSHIP BETWEEN FAMILY SUPPORT AND MATERNAL COMPLIANCE IN COMPLETE BASIC IMMUNIZATION PROVISION TO CHILDREN AGED 12-23 MONTHS IN ARUM TIMUR MELAYA}

\author{
Niken Ayu Merna Eka Sari ${ }^{1}$, Ni Made Widiawati ${ }^{2}$, A. A. Ngr. Taruma Wijaya ${ }^{3}$ \\ STIKes Wira Medika Bali ${ }^{1,2,3}$
}

\begin{abstract}
ABSTRAK
Imunisasi adalah suatu cara untuk meningkatkan kekebalan tubuh seseorang secara aktif terhadap suatu antigen, sehingga bila kelak terpapar pada antigen yang serupa, tidak terjadi penyakit. Tanpa imunisasi anak-anak mudah terserang penyakit, kecacatan dan kematian. Dukungan keluarga merupakan salah satu faktor yang berhubungan dengan kepatuhan ibu dalam pemberian imunisasi kepada bayi atau anak. Tujuan dari penelitian ini adalah mengetahui hubungan dukungan keluarga dengan kepatuhan ibu dalam pemberian imunisasi dasar lengkap. Jenis penelitian ini adalah observasional analitik dengan pendekatan cross sectional. Sampel diambil menggunakan total sampling yang terdiri dari 34 orang ibu dengan anak balita usia 12-23 bulan. Data dukungan keluarga dikumpulkan dengan menggunakan kuesioner dukungan keluarga, data kepatuhan identifikasi dilakukan dengan kuesioner kepatuhan pemberian imunisasi dasar lengkap. Berdasarkan uji statistik menggunakan spearman rank didapatkan $p$-value 0,001 dengan correlation coefficient 0,530 , artinya terdapat hubungan yang sedang antara dukungan keluarga dengan kepatuhan ibu dalam pemberian imunisasi dasar lengkap. Berdasarkan hasil ini diharapkan agar keluarga memberi dukungan kepada ibu dan anak untuk melaksanakan imunisasi sesuai jadwal karena imunisasi sangat penting untuk mencegah terjadinya penyakit serta menurunkan komorbiditas pada anak-anak Kata Kunci: dukungan keluarga, imunisasi, kepatuhan
\end{abstract}

\footnotetext{
ABSTRACT

Immunization is a way to boost a person's immune actively to an antigen, when exposed again to a similar antigen, no disease occurs. Without immunization the children are susceptible to disease, disability and death. Family support is one of the factors associated with maternal obedience in immunization to infants or children. The purpose of this study was to determine the relationship of family support to maternal obedience in the provision of complete basic immunization. The type of this research was observational analytic with cross sectional approach. Samples were taken using a total sampling consisting of 34 mothers with children aged 12-23 months. Family support data were collected using a family support questionnaire, identification compliance data were performed with a complete basic immunization compliance questionnaire. Based on statistical test using spearman rank got p-value 0,001 with correlation coefficient 0,530, meaning there was relation between family support with maternal obedience in giving complete basic immunization. Based on these results it is expected that families provide
} 
support to mothers and children to carry out immunization on schedule because immunization is very important to prevent the occurrence of disease and reduce comorbidity in children

Keywords: family support, immunization, adherence

\begin{tabular}{ll}
\hline $\begin{array}{l}\text { Alamat Korespondensi } \\
\text { Email }\end{array}$ & $\begin{array}{l}\text { Gatot Subroto I Gg.Merta Ayu No.14 Denpasar } \\
\text { : nikenmerna@yahoo.co.id }\end{array}$ \\
\hline
\end{tabular}

\section{PENDAHULUAN}

Imunisasi adalah suatu cara untuk meningkatkan kekebalan tubuh seseorang secara aktif terhadap suatu antigen, sehingga bila kelak ia terpapar pada antigen yang serupa, tidak terjadi penyakit (Malik, 2015). Imunisasi juga merupakan salah satu cara untuk menurunkan morbiditas pada bayi dan anak-anak (Agboola et al, 2015). Pemerintah mewajibkan setiap anak untuk mendapatkan imunisasi dasar terhadap tujuh macam penyakit. Penyakit tersebut antara lain: TBC, Difteria, Tetanus, Batuk Rejan (Pertusis), Polio, Campak (Measles, Morbili) dan Hepatitis $\mathrm{B}$, yang termasuk dalam Program Pengembangan Imunisasi (PPI) meliputi imunisasi BCG, DPT, Polio, Campak dan Hepatitis B. Imunisasi lain yang tidak diwajibkan oleh pemerintah tetapi tetap dianjurkan antara lain terhadap penyakit gondongan (mumps), rubella,tifus, radang selaput otak (meningitis), Hepatitis A dan cacar air (chicken pox, varicella) (Kadir dkk, 2014). Kementerian Kesehatan Republik Indonesia (2014) menyatakan bahwa balita dinilai mendapatkan imunisasi lengkap apabila mendapatkan imunisasi Hepatitis B (HB0), BCG, DPT/HB 1, DPT/HB-2, DPT/HB-3, polio-1, polio-2, polio-3, polio 4 dan campak tidak lewat dari usia 1 tahun. Pada beberapa kasus, imunisasi yang diberikan lebih dari satu kali seperti hepatitis B, DPT dan polio, bila diberikan kurang dari ketentuan yang ditetapkan kemudian dilanjutkan dengan imunisasi lain, maka imunisasi dinyatakan tidak lengkap.

Keluarga adalah dua atau lebih dari dua individu yang tergabung karena hubungan darah, hubungan perkawinan atau pengangkatan dan mereka hidup dalam satu rumah tangga, berinteraksi satu sama lain dan di dalam perannya masingmasing menciptakan serta mempertahankan kebudayaan. Anggota keluarga memandang bahwa orang yang bersifat mendukung selalu siap memberikan pertolongan dan bantuan jika diperlukan (Friedman, 2010). Jadi, dapat disimpulkan bahwa yang dimaksud dengan keluarga adalah seluruh anggota yang ada dalam sebuah rumah dan memiliki ikatan darah. Selain orang tua, anggota keluarga yang lain seperti: kakek, nenek, kakak, adik, paman, bibi dan anggota keluarga lainnya dapat memberikan dukungan jika diperlukan.

Kepatuhan merupakan perubahan perilaku atau kepercayaan seseorang sebagai dari akibat adanya tekanan kelompok yang terdiri dari pemenuhan dan penerimaan, serta mengikuti peraturan atau perintah langsung yang diberikan kepada suatu kelompok maupun individu (Myers, 2012). Ibu merupakan anggota keluarga yang memiliki kedekatan darah paling dekat dengan anak. Tidak sedikit ibu yang tidak bersedia untuk mengimunisasikan anaknya dengan alasan yang sangat sederhana yaitu kondisi sosio demografi, ketepatan waktu pelayanan imunisasi, promosi kesehatan, kondisi ekonomi masyarakat, budaya masyarakat dan kondisi wilayah. 
Berdasarkan data dari Riskesdas Bali tahun 2013 ditemukan bahwa dari 9 kabupaten/kota, kabupaten Jembrana memiliki persentase imunisasi dasar pada anak umur 12-59 bulan yang paling rendah dibandingkan dengan kabupaten lainnya. Imunisasi HB-0 hanya mencapai $84 \%$, BCG 89,5\%, DPT-HB-3 77,7\%, polio $489,5 \%$ dan campak $83 \%$. Ini menunjukkan bahwa masih adanya anak yang tidak mendapatkan imunisasi lengkap. Jika dipersentase keseluruhan anak di Jembrana, persentase yang imunisasi lengkap hanya 72,2\%, tidak lengkap 22,2 \%, sisanya sebesar 5,6\% tidak mendapatkan imunisasi sama sekali. Data dari profil kesehatan kabupaten Jembrana tahun 2016 yang diterbitkan pada tahun 2017, ditampilkan data bahwa puskesmas yang wilayah kerjanya yang paling banyak tidak imunisasi adalah puskesmas II Melaya. Kelengkapan imunisasi dasar pada puskesmas ini sebesar 94, 4\%. Imunisasi yang paling banyak tidak lengkap adalah imunisasi campak.

Tanpa imunisasi anak-anak mudah terserang penyakit, kecacatan dan kematian. Imunisasi merupakan benteng utama untuk menurunkan angka kesakitan kecacatan, dan kematian akibat beberapa penyakit, seperti tuberkulosis (TB), difteri, pertusis (batuk rejan/batuk 100 hari), hepatitis B, polio, dan campak (Maimunah, 2017). Berdasarkan masalah yang telah dibahas tersebut, dukungan keluarga merupakan salah satu faktor yang berhubungan dengan kepatuhan ibu dalam pemberian imunisasi kepada bayi atau anak. Untuk mengetahui dan menggali lebih dalam, peneliti akan melakukan penelitian dan menganalisa hubungan dukungan keluarga dengan kepatuhan ibu dalam pemberian imunisasi dasar lengkap pada balita usia 12-23 bulan di wilayah kerja Puskesmas II Melaya.

\section{BAHAN DAN METODE}

Penelitian ini menggunakan rancangan penelitian observasional analitik dengan pendekatan case control (Budiman, 2011). Penelitian ini dilakukan di Lingkungan Arum Timur Wilayah Kerja Puskesmas II Melaya Jembrana. pada bulan Mei 2018. Populasi pada penelitian ini adalah seluruh ibu dengan balita usia 12-23 bulan di Lingkungan Arum Timur. Teknik sampling pada penelitian ini menggunakan total sampling. Kriteria inklusi pada penelitian ini yaitu ibu bersedia menjadi subjek penelitian, ibu bisa baca tulis, anak memiliki KMS sebagai bukti kelengkapan imunisasi, ibu tinggal serumah minimal dengan suami atau anggota keluarga lainnya. Kriteria eksklusi dalam penelitian ini yaitu ibu dengan balita yang memiliki penyakit TBC, difteri, polio, hepatitis B, campak atau penyakit lainnya yang menyebabkan kontraindikasi untuk dilakukan imunisasi. Riwayat penyakit didapat dari hasil wawancara dan data riwayat penyakit dari puskesmas. Jumlah sampel dari penelitian ini adalah 34 orang. Variabel dalam penelitian ini adalah dukungan keluarga dan kepatuhan imunisasi dasar lengkap. Alat ukur dukungan keluarga dan kepatuhan imunisasi dasar berupa kuesioner yang telah dilakukan uji validitas dan reliabilitas.

HASIL

Tabel 1. Dukungan Keluarga

\begin{tabular}{lll}
\hline $\begin{array}{l}\text { Dukungan } \\
\text { Keluarga }\end{array}$ & Frekuensi (n) & $\begin{array}{l}\text { Persentase } \\
(\%)\end{array}$ \\
\hline Buruk & 3 & 8,8 \\
\hline Baik & 31 & 91,2 \\
\hline
\end{tabular}




\begin{tabular}{lll}
\hline Total & 34 & 100,0 \\
\hline
\end{tabular}

Dari tabel di atas diketahui bahwa dari hasil pengisian kuesioner dukungan keluarga didapatkan sebagian besar responden yaitu sebanyak 31 responden $(91,2 \%)$ responden memiliki dukungan keluarga yang baik.

Tabel 2. Kepatuhan Imunisasi Dasar Lengkap

\begin{tabular}{lll}
\hline $\begin{array}{l}\text { Tingkat } \\
\text { Keseimbangan Tubuh }\end{array}$ & Frekuensi (n) & Persentase (\%) \\
\hline Baik & 6 & 54,5 \\
\hline Sedang & 4 & 36,4 \\
\hline Buruk & 1 & 9,1 \\
\hline Total & 11 & 100 \\
\hline
\end{tabular}

Dari tabel di atas diketahui bahwa dari hasil pengisian kuesioner kepatuhan imunisasi dasar lengkap didapatkan sebagian besar responden yaitu sebanyak 30 responden $(88,2 \%)$ patuh dalam pemberian imunisasi dasar lengkap.

Tabel 3. Tabel Hubungan Dukungan Keluarga dengan Kepatuhan Imunisasi Dasar Lengkap pada Balita Usia 12-23 Bulan

\begin{tabular}{|c|c|c|c|c|c|}
\hline & & \multicolumn{2}{|c|}{ Kepatuhan Imunisasi } & & $\mathrm{P}$ \\
\hline & & Tidak patuh & Patuh & Total & $\mathrm{R}_{2}$ \\
\hline \multirow{2}{*}{$\begin{array}{l}\text { Dukunga } \\
\mathrm{n} \\
\text { keluarga }\end{array}$} & $\begin{array}{l}\text { Dukungan } \\
\text { keluarga buruk }\end{array}$ & 2 & 1 & 3 & \multirow{4}{*}{$\begin{array}{c}0,0010,53 \\
0\end{array}$} \\
\hline & $\begin{array}{l}\text { Dukungan } \\
\text { keluarga baik }\end{array}$ & 2 & 29 & 31 & \\
\hline \multirow{2}{*}{\multicolumn{2}{|c|}{ Total }} & & & & \\
\hline & & 4 & 30 & 34 & \\
\hline
\end{tabular}

Hasil uji statistik mendapatkan $p$ value sebesar 0,001 yang artinya bahwa $p$ value $<\alpha$ dengan $\alpha=0,05$. Maka secara statistik ada hubungan yang signifikan antara dukungan keluarga dengan kepatuhan imunisasi dasar lengkap. Kuat lemahnya hubungan variabel dilihat dari koefisien korelasi $(0,530)$ menunjukkan korelasi yang sedang antar kedua variabel. Sifat korelasi/hubungan adalah positif, dapat diketahui dari nilai koefisien korelasi yang nilainya positif. Artinya, semakin baik dukungan keluarga maka semakin patuh terhadap pemberian imunisasi dasar. Hasil uji rank spearman sebesar 0,530 memiliki makna bahwa 53\% kepatuhan imunisasi dasar legkap berhubungan dengan dukungan keluarga, sedangkan sisanya dipengaruhi oleh faktor lain. 


\section{PEMBAHASAN}

Berdasarkan penelitian yang telah dilakukan peneliti hasil uji statistik mendapatkan $p$ value sebesar 0,001 yang artinya bahwa $p$ value $<\alpha$ dengan $\alpha=0,05$. Maka secara statistik ada hubungan yang signifikan antara dukungan keluarga dengan kepatuhan imunisasi dasar lengkap. Koefisien korelasi $(0,530)$ menunjukkan korelasi yang sedang antar kedua variabel. Sifat korelasi/hubungan adalah positif yang artinya, semakin baik dukungan keluarga maka semakin patuh terhadap pemberian imunisasi dasar.

Kepatuhan adalah komitmen seseorang terhadap suatu nilai. Kepatuhan (adherence) adalah istilah yang digunakan untuk menggambarkan perilaku seseorang dalam pemberian upaya pencegahan penyakit secara benar. Kepatuhan dalam pemberian imunisasi dasar adalah salah satu perilaku kesehatan. Dalam teori perilaku menurut Scehandu B Karr dalam Notoatmodjo (2012) terdapat 5 determinan (alasan pokok) perilaku (behavior), yaitu intention (adanya niat seseorang untuk bertindak), dukungan sosial (adanya dukungan sosial dari keluarga dan masyarakat sekitar), accessibility of information (keterjangkauan informasi), personal autonomi (otonomi dan kebebasan pribadi) dan action situation (adanya kondisi dan situasi yang memungkinkan).

Dukungan keluarga adalah bantuan yang diterima oleh salah satu anggota keluarga dari keluarga lainnya dalam rangka menjalankan fungsi keluarga. Keluarga merupakan unit terkecil yang terdekat dengan pasien sehingga keluarga dalam menjadi motivator yang baik dalam peningkatan derajat kesehatan anggota keluarga yang lain (Kusumaningrum, 2017). Menurut Niven (2012), keluarga dapat menjadi faktor yang sangat berpengaruh dalam menentukan keyakinan dan nilai kesehatan individu serta dapat juga menentukan tentang program pencegahan penyakit yang dapat mereka terima. Dukungan keluarga dalam bentuk dukungan dari anggota keluarga merupakan faktor penting dalam kepatuhan terhadap program-program medis.

Hasil penelitian ini sejalan dengan hasil penelitian yang dilakukan oleh Supriatin (2015) yang meneliti hubungan antara dukungan keluarga dengan kepatuhan/ketepatan waktu pemberian imunisasi campak. Penelitian ini dilaksanakan di wilayah kerja Puskesmas Pasir Kaliki Bandung pada bulan Februari-Maret 2014. Penelitian ini menggunakan 86 orang responden. Berdasarkan pengolahan data secara univariat untuk dukungan keluarga diperoleh data sebagai berikut: dukungan baik sejumlah 53 orang $(61,63 \%)$ dan dukungan kurang 33 orang $(38,37 \%)$. didapatkan p-value sebesar $0,027<0,05$. Hal ini menunjukan bahwa terdapat hubungan yang bermakna antara dukungan keluarga dengan ketepatan waktu ibu dalam pemberian imunisasi campak. Data dukungan keluarga dikumpulkan dengan cara yang sama dengan penelitian ini, yaitu dengan menggunakan kuesioner.

Penelitian lain dilakukan oleh Jayanti (2017) dalam penelitiannya yang berjudul "Effects of Predisposing, Enabling, and Reinforcing Factors on Completeness of Child Immunization in Pamekasan, Madura". Sekitar 80.0\% ibu dengan dukungan keluarga kuat memiliki status imunisasi lengkap sedangkan $60.0 \%$ ibu dengan dukungan keluarga lemah memiliki status imunisasi tidak lengkap. Hasil analisis dengan uji Chi Square menunjukkan ada hubungan yang 
bermakna antara jarak ke pelayanan kesehatan dengan perilaku perolehan imunisasi $(\mathrm{OR}=60.0$; CI 95\%=2.7 hingga 13.2; $<<0.001)$.

Peneliti berpendapat, dukungan keluarga memiliki hubungan dengan kepatuhan pemberian imunisasi dasar. Tingkat kekuatan hubungan yang dimiliki antara kedua variabel ini adalah sedang. Ini ditunjukkan dari hasil penelitian yang mendapatkan p-value sebesar 0,001 dan koefisien korelasi sebesar 0,530. Semakin tinggi dukungan keluarga, semakin patuh pula kepada pemberian imunisasi dasar. Dalam hal ini, anggota keluarga yang paling dekat adalah suami. Dukungan sosial dari suami merupakan dorongan kuat untuk memberikan yang terbaik dalam menjaga kesehatan anak.

\section{Simpulan}

\section{SIMPULAN DAN SARAN}

Berdasarkan hasil penelitian tersebut dapat dilihat ada hubungan yang signifikan antara dukungan keluarga dengan kepatuhan imunisasi dasar lengkap. Koefisien korelasi $(0,530)$ menunjukkan korelasi yang sedang antar kedua variabel. Sifat korelasi/hubungan adalah positif yang artinya, semakin baik dukungan keluarga maka semakin patuh terhadap pemberian imunisasi dasar.

\section{Saran}

Kepada Puskesmas

Dari hasil penelitian didapatkan $80 \%$ responden sebanyak $88,2 \%$ responden patuh dalam pemberian imunisasi dasar lengkap. Itu artinya, masih $11,8 \%$ yang tidak patuh dalam pemberian imunisasi dasar lengkap. Untuk mencapai target UCI yang menargetkan $100 \%$ anak harus mendapatkan imunisasi lengkap, disarankan kepada pihak Puskesmas II Melaya untuk meningkatkan pencapaian cakupan imunisasi menjadi $100 \%$.

Kepada Peneliti Selanjutnya

Bagi peneliti selanjutnya, hasil penelitian ini bisa digunakan sebagai bahan pertimbangan untuk mengembangkan penelitian selanjutnya dengan melakukan analisis faktor-faktor lain yang mempengaruhi dukungan keluarga dan kepatuhan pemberian imunisasi dasar diantaranya adalah tingkat pengetahuan ibu, sikap petugas dan jarak rumah dengan fasilitas penyedia layanan imunisasi.

Kepada Masyarakat

Kepada masyarakat, agar memberi dukungan kepada ibu dan anak untuk melaksanakan imunisasi sesuai jadwal karena imunisasi sangat penting untuk mencegah terjadinya penyakit serta menurunkan komorbiditas pada anak-anak.

\section{DAFTAR PUSTAKA}

Agboola et al. 2015. Knowledge, attitude, perceptions of adult males towardschildhood immunizations in southwest Nigeria.American Journal of Health Research. 3(1): 8-12

Budiman. 2011. Penelitian Kesehatan Buku Pertama. Bandung: PT. Refika Aditama

Friedman, M.M. 2010. Buku Ajar Keperawatan Keluarga: Riset, Teori dan Praktek. Jakarta : EGC. 
Jayanti, dkk. 2017. Effects of Predisposing, Enabling, and Reinforcing Factors on Completeness of Child Immunization in Pamekasan, Madura. Journal of Epidemiology and Public Health. 2(2): 106-118

Kadir dkk. 2014. Pengetahuan dan Kepatuhan Ibu pada Pemberian Imunisasi Dasar bagi Bayi. Journal of Pediatric Nursing. 1(1): 9-13

Kementerian Kesehatan Republik Indonesia. 2014. Buku Ajar Imunisasi. Jakarta: Pusat Pendidikan dan Pelatihan Tenaga Kesehatan

Kusumaningrum. 2017. Hubungan Tingkat Pendidikan dan Dukungan Keluarga terhadap Kepatuhan Diet pada Pasien Gastritis Rawat Inap di RSUD Sukoharjo. Karya tulis diterbitkan. Surakarta: Universitas Muhammadiyah

Maimunah. 2017. Hubungan Pengetahuan Ibu dengan Pelaksanaan Imunisasi Dasar pada Bayi di Desa Karang Sari Huta 3 Kecamatan Gunung Maligas Kabupaten Simalungun. Jurnal Keluarga Sehat Sejahtera. 15(29): 31-37

Malik, I. 2015. Cakupan Imunisasi Dasar dengan Kejadian ISPA pada Balita Usia 1-3Tahun di Wilayah Puskesmas Wonosari 1 Kabupaten Gunungkidul. Journal Ners and Midwifery Indonesia.3(1): 53-57

Myers, D.G. 2012.Psikologi Sosial Jilid 2. Jakarta: Salemba Medika

Niven. 2012. Psikologi Kesehatan: Pengantar untuk Perawat dan Profesional Kesehatan Lain. Jakarta: EGC

Notoatmodjo S. 2012. Promosi Kesehatan dan Perilaku Kesehatan. Jakarta: PT Rineka Cipta

Supriatin, E. 2015. Hubungan Pengetahuan dan Dukungan Keluarga dengan Ketepatan Waktu Pemberian Imunisasi Campak Di Pasir Kaliki Bandung.Jurnal Ilmu Keperawatan. 3(1): 1-10 